Article

\title{
Life Cycle Assessment and Cost Analysis of Additive Manufacturing Repair Processes in the Mold Industry
}

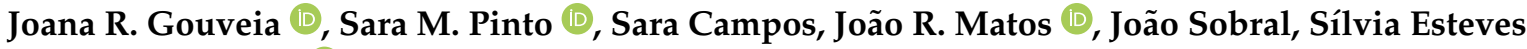 \\ and Luís Oliveira *
}

check for updates

Citation: Gouveia, J.R.; Pinto, S.M.; Campos, S.; Matos, J.R.; Sobral, J.; Esteves, S.; Oliveira, L. Life Cycle Assessment and Cost Analysis of Additive Manufacturing Repair Processes in the Mold Industry. Sustainability 2022, 14, 2105 https://doi.org/10.3390/su14042105

Academic Editor: Alessia Amato

Received: 15 December 2021

Accepted: 8 February 2022

Published: 12 February 2022

Publisher's Note: MDPI stays neutral with regard to jurisdictional claims in published maps and institutional affiliations.

Copyright: (C) 2022 by the authors. Licensee MDPI, Basel, Switzerland. This article is an open access article distributed under the terms and conditions of the Creative Commons Attribution (CC BY) license (https:// creativecommons.org/licenses/by/ $4.0 /)$.
INEGI-Instituto de Ciência e Inovação em Engenharia Mecânica e Engenharia Industrial, 4200-465 Porto, Portugal; jrgouveia@inegi.up.pt (J.R.G.); smpinto@inegi.up.pt (S.M.P.); scampos@inegi.up.pt (S.C.); jrmatos@inegi.up.pt (J.R.M.); jsobral@inegi.up.pt (J.S.); sesteves@inegi.up.pt (S.E.)

* Correspondence: loliveira@inegi.up.pt; Tel.: +351-229-578-710

\begin{abstract}
There is a growing demand for data regarding the environmental and economic performance of additive manufacturing to establish the role of this technology in the future circular industrial economy. This paper provides a comparative analysis of direct energy deposition technology with conventional manufacturing, specifically iron casting, in the context of the repairing capabilities of the direct energy deposition system in a damaged glass bottle mold. Making use of already established methodologies for environmental and economic assessment, a life cycle assessment and a life cycle costing study was conducted on each scenario to provide a holistic perspective on the advantages and limitations of each system. With the gathered life cycle inventory, the main environmental impacts and life cycle costs were determined. The hybrid repairing scenario results show a reduction of the environmental impacts and life cycle costs by avoiding resource consumption in the production of a new mold, with underlying economic advantages identified beyond the calculated results. Through strategic integration based in life cycle approaches, it is concluded that direct energy deposition technology can play a key role in the sustainable development of tooling and manufacturing industries, especially in products with large dimensions, complex geometry, and customized design.
\end{abstract}

Keywords: life cycle assessment; life cycle costing; additive manufacturing; direct energy deposition; mold industry; sustainability; circular economy

\section{Introduction}

Additive manufacturing (AM) has become a disruptive production technology in the manufacturing industry. Its application has gone beyond prototyping and at-home production, to a positioned production strategy for the development of high-value products with complex designs and customized features.

Contrary to the common subtractive manufacturing processes, the basic principle of $\mathrm{AM}$ is the adding of material in a layer-by-layer deposition process to produce parts and components with complex geometry, making use of tridimensional (3D) models developed in digital design software. The deposition of material (either polymers, ceramics, composite, bio-based or metal) occurs through melting by a localized high-intensity heat source and deposition according to the predesigned geometry in the CAD file, followed by cooling at room temperature, generating the desired product.

The most popular AM technologies are related to polymer AM due to the low material costs and reduced sizes for consumer-based production. In an industrial setting, metal $\mathrm{AM}$ has gained a lot of interest, specifically direct energy deposition (DED) that involves the use of a laser beam as an energy source to deposit thin layers of sintered metal on a substrate that can be pre-heated [1]. The DED system operation allows for a wide range of 
applications, from repairing and rebuilding damaged components to the manufacturing of new components or equipment parts [2]. The system parameters, such as the laser power, powder feed rate, scanning speed, powder mass flow rate and coaxial powder gas flow rate, can highly influence the performance and characteristics of the printed part or component [1].

When compared with traditional manufacturing technologies, 3D printing can provide quicker prototyping, reduction of repair time and labor costs, quick and cheap production of customized high-value items, increased competitiveness and innovation capacity, elimination of excess material and new possibilities of technical properties with lower material resource consumption [3]. The industrial 3D printing technologies can potentiate an extended product lifecycle, improve resource efficiency (both in production and use phase) and innovate the conventional value chains through localized production [4]. These advantages have increased interest and investment in several applications and business opportunities as European manufacturing regulations move to a more circular business model, especially in machine tool manufacturing, with innovative possibilities for retrofitting, repairing, and refurbishment of inactive or obsolete machine tools.

Several innovative applications of AM in tooling can be found in the current literature $[3,5,6]$ and a number of successful implementations have already been conducted for different tooling fields, from automotive assembly lines to surgical medicine $[7,8]$. The production systems based on machine tooling are elementary systems of the industrial processes responsible for the production of all types of capital goods and products. The performance and efficiency of these systems are strongly dependent on the engineering solutions materialized in tooling. Thus, it is important to assess, manage and improve the efficiency of resource consumption and capital goods along the life cycle of these solutions. In this context, the environmental and economic sustainability evaluation of the technological solutions of tooling are crucial to ensure a sustainable path towards a greener and circular production ecosystem. In one study [9], the authors analyzed the use of AM to manufacture molds and dies for their potential to remove engineering scrap and reduce other harmful ancillary inputs into production. The results evidenced that AM technologies can provide a significant impact reduction in the supply chain activities of tooling manufacturing. The benefits of this technology can go beyond just production of the part, and the authors mention that the capability of this technology to repair and remanufacture tooling can translate into new tooling business models with lower waste and resource consumption.

In order to assess the environmental effects of products or technologies, the scientific community uses the broadly accepted life cycle assessment (LCA) methodology, normalized by ISO 14040 and ISO $14044[10,11]$. This approach is utilized to quantify potential environmental impacts and identify the main hotspots to establish improvement action plans and support decision making processes. The quantified environmental performance is associated with pre-established system boundaries that accurately describe the main energy and material flows that occur in the product system and that are correlated using a selected functional unit that measures the system's function as reference. The holistic approach of LCA allows us to consider the flows that occur in all life cycle stages of the product system - from extraction of raw materials to transport, production, assembly, use and end of life treatment. Regarding the economic effects, the life cycle costing (LCC) methodology can naturally complement the goal and scope of the LCA and provide the gathering and quantification of the associated costs and economic effects of the product system. This is due to the fact that LCC has a similar holistic approach to each life cycle stage, making use of a functional unit and system boundaries to characterize and define the scope of the study. This methodology is based on relevant metrics of cost-benefit analysis, including production, use and end of life costs to quantify the real profit of a product or system, for assessment of alternatives or improvement measures. Both LCA and LCC are widely used in the sustainability research field to support decision making processes [12-14] and can be applied in the assessment of the DED technological potential 
to provide support for the further development and integration of this technology in a more sustainable and circular industry.

\section{Research Gaps}

In the literature, the fact that this is an emerging technology is reflected in the lack of available information, since, specifically in the metal AM field for DED technology, publications and studies regarding environmental and economic performance are still small, contrary to the polymer AM field, where several studies can be found. One of the two LCA studies found in the literature [15] conducted a comparative LCA between traditional manufacturing and a DED system in the production of a carbon steel gear, using AISI 4140 alloy steel powder. The authors consider as a functional unit the function of the component in which the gear will operate, together with a very low powder efficiency of $14 \%$. The results indicate that the machining of the gear generates less environmental impacts than the production by DED, concluding that the powder and electricity consumption are the main drivers for the total impacts of the AM scenario. On the other hand, another study conducted in a master thesis [16] compared the environmental impacts between CNC manufactured steel turbine blades with ones produced through DED manufacturing. The end-of-life scenarios were considered equal and, as such, were excluded from the results. The scenario with more impacts, referenced per produced blade and its respective height, is the $\mathrm{CNC}$ production, due mostly to the higher energy intensity, even when considering the increment in part complexity. Since these are the only LCA studies found on DED technology, the lack of inventory data and the contrary results cannot provide a clear understanding of the DED's environmental performance.

Other environmental studies of metal AM technologies can be found, however there are several functional differences that make it difficult to compare with DED [17-19]. Some studies $[17,18]$ analyzed and compared several other AM technologies, focusing on the typical cradle-to-grave approach (extraction, production, use and disposal). In one study [18] the authors emphasized the lack of life cycle inventory (LCI) data for resource consumption and other direct or indirect emissions from the AM systems but also that there are potential environmental benefits to be accounted in the use phase of the printed products. This can be applied to the extension of the product lifetime. Another paper [19] measured the environmental impacts of an aluminum powder printing operation with an SLM system, verifying that electricity consumption is the driver of the total system impacts. Nonetheless, these results cannot be extrapolated to the DED technology since SLM uses a powder bed to conduct the printing, instead of the powder projecting operation that occurs in DED. SLM also has different operation parameters and resource consumptions. Additionally, the DED technology, unlike SLM, has the capability to restore or transform existing parts. However, there is a lack of studies of AM applications on other production activities such as repairing, retrofitting or refurbishment. This is the case for most literature, evidencing the need for studies in the applicability of AM in circular business manufacturing. Studies that compared AM with conventional manufacturing $[9,20-23]$ have shown a significant research gap for the validation of the technology in terms of performance on these capabilities. Walachowicz et al. (2017) [20] compared the AM repairing capacity with conventional manufacturing methods and, even with higher energy and inert gas consumption, the repairing generated less environmental impacts than business-as-usual (BAU) machining and welding processes.

In summary, considering the low number of studies found in the literature for DED, it is clear that there is a need to improve and increase the LCA studies of this technology, mainly in providing more accurate data and conducting a more extensive analysis on the capabilities of DED beyond part manufacturing. The variations in the performance parameters of the DED system and the lack of foreground data generate different conclusions that are not possible to compare, and thus, each new case needs a new study to determine if there are environmental gains in using $\mathrm{AM}$ and must consider the whole production system operation lifetime. Overall, there is a lack of LCI data on other AM technologies and 
the operation parameters (as well as resource consumption), can vary greatly. Additionally, the potential of AM in terms of impact reduction through lower waste generation and lower consumption of resources is evidenced in the current literature. This potential can be validated through the DED capability of repairing and refurbishing products or parts.

In terms of the economic assessment of DED systems, there is a lack of studies focused on this specific AM technology. In other AM LCC studies, one paper [24] identified significant potential cost reductions in small to medium batch productions through AM when the component shape is adapted to the specifications of the manufacturing operation procedure and parametrization. The authors concluded that most production costs are related to the machine cost amortization per part. Another paper [25] emphasized this issue, mentioning that economic models that do not consider the capital costs related to the acquisition and setup phase can limit comparability between AM and other conventional manufacturing systems. It was also indicated that there is a research gap regarding the impact of AM in production costs in complex design industries. The potential opportunities of implementing AM for complex design is also identified in another study [26] that developed a cost model from powder production to the recycling of the metal part and determined that there is a high level of competitiveness and economic advantage in AM for this sector, especially for complex design products with large dimensions. A recent overall literature review [27] on the sustainability assessment of AM concluded that most studies focus on less subjective parameters that are easier to assess and provide clear results.

Considering the existing research gaps, the purpose of this study was to quantify the potential of AM technology, specifically direct energy deposition (DED), in terms of environmental and economic performance in the context of integration in a sustainable industry development, specifically in the European mold industry. It is important to assess and quantify the environmental and economic performance of this emerging technology, in order to establish its role in the manufacturing industry for an optimized use of its potential in the reduction of environmental impacts, production costs and drive design innovation for high-value products. Through the gathering of foreground data, an LCA and an LCC study was conducted in the use of the DED system to repair a damaged glass bottle mold. This paper provides foreground LCI data, collected from suppliers and measurements taken in situ, as well as environmental and economic key performance indicators for DED applications through the lenses of sustainable manufacturing. The focus is the environmental and economic assessment of the applicability of DED in tooling, assessing a repairing process instead of mass production, to reduce waste, extend the tool lifetime and avoid potential environmental damage. The findings of this paper can also be applied in refurbishment and retrofitting activities.

Firstly, in Section 2, a case study of a repairing process of a glass bottle mold is presented, together with the definition of the system boundaries and collected inventory. Then, in Section 3, the gathered inventory is analyzed through LCA and LCC methodologies, by conducting a comparison between conventional manufacturing and the repairing system. Finally, in Section 4, the main conclusions and limitations are presented.

\section{Materials and Methods}

\subsection{Life Cycle Thinking Approach}

The chosen approach for this assessment is based on life cycle thinking [28-30], which implies considering all of the value chain leading up to the desired final product or production process and its performance in the environmental, social and economic dimensions. This paper focuses on the environmental and economic aspects. In this case, an attributional LCA was conducted to quantify the main environmental impacts using the framework standardized by ISO 14040 and ISO $14044[10,11]$ that consists of four phases:

- Goal and Scope;

- $\quad$ Life Cycle Inventory;

- Life Cycle Impact Assessment;

- Interpretation. 
The LCC methodology follows the same phases, but accounting for economic values rather than mass and energy flows. In an LCA study, the first phase defines the main purpose of the study and the scope, range, geography, magnitude and limits of the system boundaries. In this phase, a functional unit is selected to be the reference value from which the environmental impacts will be presented and quantified. The second phase is the gathering of data regarding the main inputs and outputs of mass and energy (costs in the case of LCC) that occur within the previously defined boundaries with the help of foreground data, literature, life cycle databases and others. With the collected information, the third phase consists of using environmental indicators to convert the collected flows into environmental impacts, usually making use of well-established quantification methods and software. The last phase evaluates the outcomes to draw conclusions for decision makers and of the study itself as whether there is a need to change the scope, data or other parameters to better reach the initial goal.

The LCC method has the same goal and scope of the LCA study and has as a main purpose the quantification of all the associated costs within the life cycle, from the perspective of one or more stakeholders or interested parties. For this study the costs were calculated considering the perspective of the tooling user.

The following subsections present the case study for the DED system, together with the goal and scope, including system boundaries, functional unit, and limitations for the LCA and LCC.

\subsection{Case Study—Goal and Scope}

The analyzed case study involved a damaged cast iron mold for glass bottles from an industrial manufacturer (Figure 1). The main purpose of the LCA and LCC study is to analyze the performance of a hybrid manufacturing process (combination of subtractive and additive manufacturing) for the repairing of the damaged mold, in order to extend its lifetime and avoid the consumption of resources to produce a new mold.

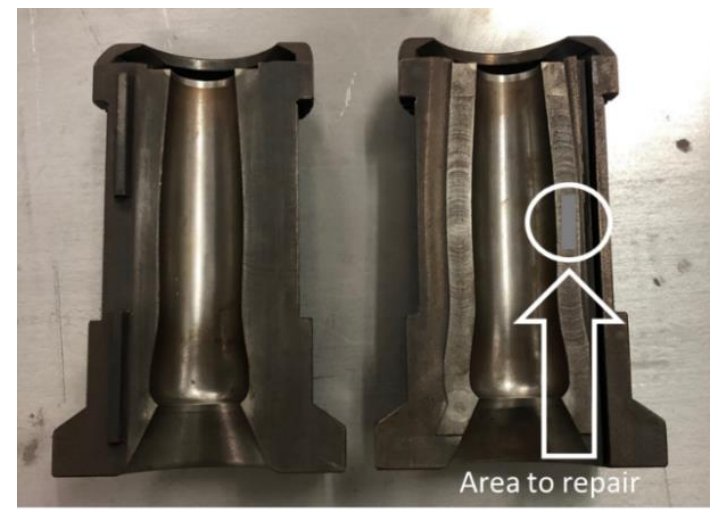

Figure 1. Case study: damaged mold for glass bottles.

The LCA and LCC study intended to identify and quantify the main environmental and economic hotspots (respectively) of the repairing process, as well as compare the hybrid manufacturing with a conventional BAU scenario-discarding and production of a new mold by sand casting, with a final machining. The hybrid process involves three steps: initial machining of the damaged area, deposition of material with DED technology and final machining to obtain the desired features. The system boundaries of the environmental and the economic analysis are presented in Figure 2. 


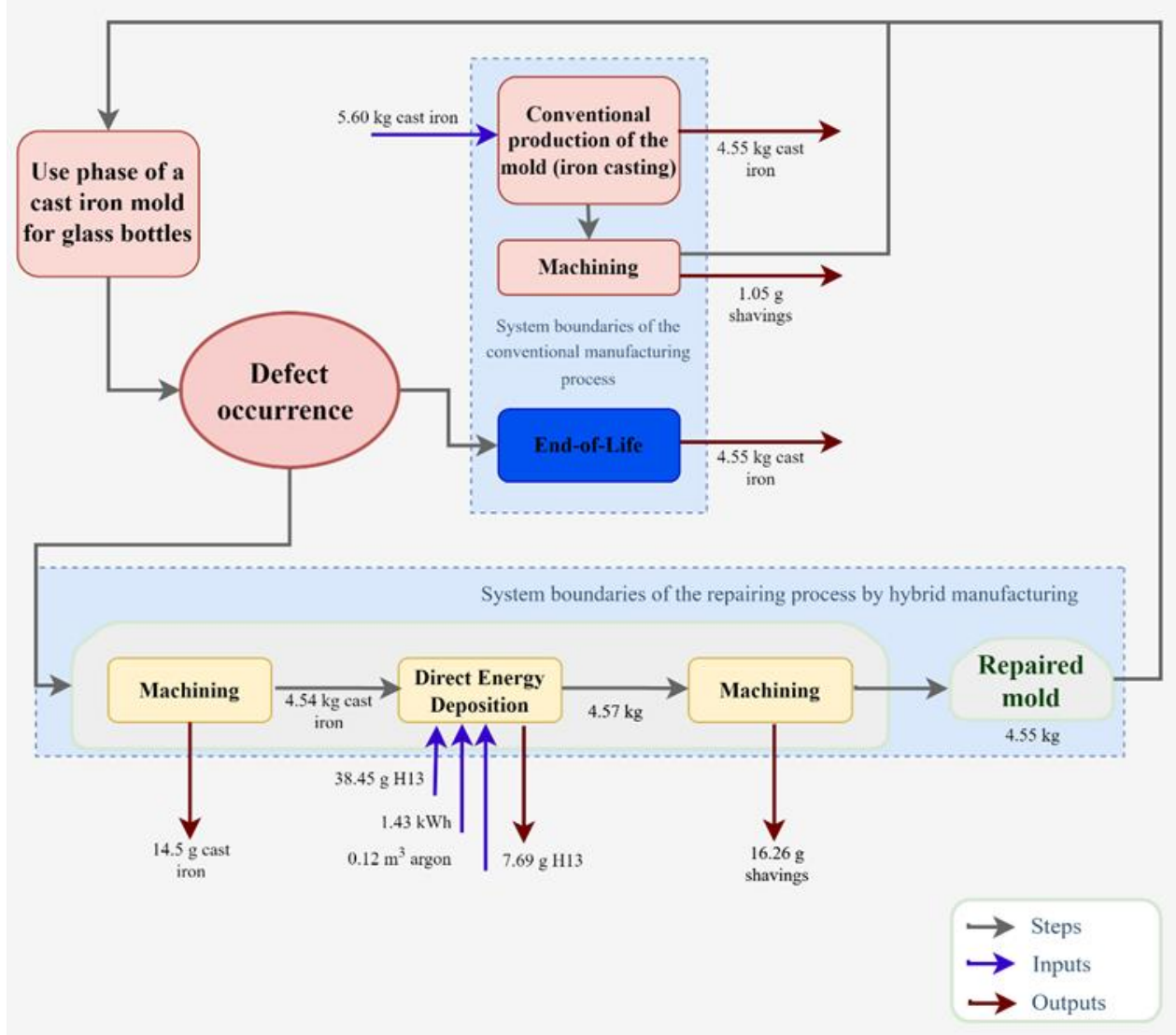

Figure 2. System boundaries of the possible routes of the damaged cast iron mold and respective input and output flows for each scenario.

Following the conventional scenario, the mold would be discarded and a new one produced. On the other hand, with the repairing process, the damaged mold is directed towards the hybrid manufacturing process where the affected area is machined and then goes to the DED system where H13 hot work tool steel (Oerlikon AM) powder is deposited in the part, rebuilding the previously machined area in 4.5 minutes. After the AM process, the mold is machined again to give the shape and finishing required, being then ready for the glass bottle manufacturer that will make use of the mold for longer. This approach allows a shorter response time to restore the mold.

The LCA and LCC studies focused on the processes that occur when the mold arrives already damaged to the hybrid manufacturing process, analyzing the machining to remove the damaged area, the deposition of H13 steel powder with DED technology to fill the damage and the final machining process. Additionally, the study considered that the repaired mold can only last a third of the total 125,000 cycles sustained by a newly produced mold. As such, the inventory of the repairing will be gathered per repair process for transparency purposes and for better understanding. In the results, the presented environmental impacts and economic costs are correspondent to a total of three repairs. The selected functional unit-from which the energy, mass, and cost flows as well as the environmental and economic impacts will be normalized-was one functional mold, weighing $4.55 \mathrm{~kg}$ and with a durability of 125,000 cycles.

\subsection{Life Cycle Inventory}

The data gathering for the characterization of materials and energy consumption of the DED system has already been conducted in another study [31], where the information was collected in situ and mostly through direct suppliers and operators, except for the chiller, where the data was gathered from a similar system [19]. For the economic data regarding purchase and assembly of the DED, information from consumables, powder and 
argon were supplied by the developers of the system, making use of previously installed sensors. Regarding the background data, life cycle database Ecoinvent v3.7.1 [32] was used to obtain information regarding supply chains and raw material extraction activities, as well as to match the identified flows with the correct processes in the database (see Appendix A for Table A1, regarding the Ecoinvent matching processes for the conventional production scenario and Table A2, regarding the Ecoinvent matching processes for the hybrid repair scenario). Some of the dataset was adapted when necessary to accurately describe the links between activities and resource flows. The production and assembly of the machining equipment was also obtained from the database as it is integrated in the Ecoinvent processes for milling. To accurately represent the environmental impacts of the DED system in the repairing activities, it was necessary to characterize the use phase of the DED for this specific case study, considering the deposition time for each repair, operation conditions per year and the total lifetime of the DED system. The values considered for these parameters are presented in Table 1, to characterize a scenario where a DED system is used to repair a similarly damaged mold for a total lifetime of 10 years, independently of the machining activities of the hybrid repairing system.

Table 1. Characterization parameters for the use phase of the DED system.

\begin{tabular}{|c|c|c|}
\hline Parameters & Units & Value \\
\hline Time for DED deposition in one mold & hour & 0.0749 \\
\hline Time for switching between molds & hour & 0.0167 \\
\hline Daily DED operation time & hour & 4.00 \\
\hline Daily number of repairs & - & 43 \\
\hline DED lifetime & year & 10 \\
\hline Number of total lifetime repairs & - & 110,536 \\
\hline
\end{tabular}

The amount of DED system to consider for each deposition in order to distribute the impacts of the system's production, is the inverse of the total lifetime depositions carried out by the DED-9.19 $\times 10^{-6} \mathrm{p}$ (amount) of DED system per deposition. The primary flows of material and energy consumption are presented in Figure 2 for each scenario. For the repairing scenario, the production of $\mathrm{H} 13$ steel powder through atomization was also considered, making use of data from one paper [15]. According to the available literature, the DED powder usage efficiency (percentage of powder that is melted into the product) can vary from $14 \%$ [15] to $90 \%$ [33]. For this study, an optimized scenario was considered with an average $80 \%$ of powder efficiency, where the DED system is operating within an industrial setting, in a production line for the repairing of glass bottle molds. The main resource flows in this scenario are the electricity consumption during machining steps and DED, as well as argon and powder from the DED system. In the conventional BAU scenario, the new mold is produced through iron casting and final machining. The waste generated from each scenario and the damaged mold in the BAU scenario are assumed to go to landfill. Whenever necessary, data from similar processes were considered and mass proxies were used to fill any lack of information. From the Ecoinvent database, it was possible to estimate the flows from producing cast iron, as well as the machining processes and the end-of-life treatment (landfill). The existing energy consumption process in the database for Portugal was updated to the energy mix from August 2019 and August 2020, through the available information from APREN [34] and DGEG [35]. With the use phase scenarios characterized, the associated costs for the consumption of materials and energy were calculated and are presented in Table 2 for the repairing scenario. It is assumed that a conventionally produced mold costs $1000 €$ for a glass bottle manufacturer. 
Table 2. Energy and material costs during the use phase of the hybrid system, for one repair.

\begin{tabular}{lcc}
\hline \multicolumn{1}{c}{ Material and Energy Flows } & Consumption Per Mold & Costs ${ }^{\mathbf{1}}$ \\
\hline Electricity for initial machining $^{1}$ & $0.3048 \mathrm{kWh}$ & $€ 0.04$ \\
Electricity for deposition $^{1}$ & $1.4345 \mathrm{kWh}$ & $€ 0.19$ \\
Powder (H13) $^{2}$ & $38.45 \mathrm{~g}$ & $€ 1.87$ \\
Argon $^{2}$ & $0.1234 \mathrm{~m}^{3}$ & $€ 2.55$ \\
Electricity for final machining $^{1}$ & $0.0109 \mathrm{kWh}$ & $€ 0.001$ \\
\hline
\end{tabular}

${ }^{1}$ Cost data collected from invoices. ${ }^{2}$ Cost data collected for industrial users from Portugal in 2021 [36].

The argon consumption is the costliest flow from the repairing system, followed by the H13 powder. These material flows can vary greatly, depending on the complexity of the product that is being produced. This generates a great number of discrepancies in economic analysis results, since the costs can overcome the conventional production costs. An analysis on this issue is presented in Section 3.3. For the acquisition of machinery, the invoices related to the purchase and assembly of equipment were gathered and inventoried. The machining equipment is considered to be already present in the installations of the manufacturer due to its broad usage in the industry, and only the DED system needs to be purchased. The maintenance costs related to the activity of the DED system are mainly from small repairs and consumables (filters for the chiller, chiller water, additives, degreasing chemicals and tape). Inactivity costs are mostly for cleaning of the space, security, and rental of the area. Due to confidentiality issues, these values cannot be presented.

\section{Results \& Discussion}

\subsection{Life Cycle Assessment (LCA)_Environmental Impact Assessment}

With the gathered information, the life cycle impact assessment was conducted to determine the environmental performance of each scenario. The results were obtained in the LCA software Simapro v9.1.0.7 [37] and the selected quantification method was ReCiPe 2016 v1.1 [38] Endpoint (H) in Ecopoints (pts) to characterize the environmental effects on the most relevant impact categories in the literature.

To determine the environmental impact categories that are more relevant for this type of technology and avoid bias in the assessment of the environmental performance, an analysis of the available literature on LCA of AM was conducted. A total of 18 papers were assessed on the used LCIA methodology and impact methods [9,15,17,19-23,39-48]. Each impact category was scored from one to ten, according to the number of times it appears in the literature. Equation (1) presents the weighting score calculation conducted to assess each impact category.

$$
\text { number of papers of the category } \times \frac{\text { maxscore }}{\text { total number of papers }}=\text { weighting score }
$$

The identified impact categories and the respective score points are presented in Table 3. For this study, the maximum score is 10 and the total number of papers is 18. For example, considering that the Global Warming category, expressed in $\mathrm{kg} \mathrm{CO}_{2}$ eq., is present in all the analyzed papers; the weighting score for this category is 10. 
Table 3. Parameters for homogenizing the results for the selected functional unit.

\begin{tabular}{ccc}
\hline$\#$ & Environmental Impact Categories Analyzed in LCA of AM & Weighting Scores \\
\hline 1 & Global warming & 10 \\
2 & Land use & 6 \\
3 & Ozone formation, Human health & 4 \\
4 & Ozone formation, Terrestrial ecosystems & 4 \\
5 & Terrestrial acidification & 4 \\
6 & Fossil resource scarcity & 4 \\
7 & Fine particulate matter formation & 3 \\
8 & Freshwater eutrophication & 3 \\
9 & Ionizing radiation & 2 \\
10 & Terrestrial ecotoxicity & 2 \\
11 & Freshwater ecotoxicity & 2 \\
12 & Marine ecotoxicity & 2 \\
13 & Human carcinogenic toxicity & 2 \\
14 & Human non-carcinogenic toxicity & 2 \\
15 & Mineral resource scarcity & 3 \\
16 & Marine eutrophication & 2 \\
17 & Water consumption & 1 \\
18 & Stratospheric ozone depletion & 1 \\
\hline
\end{tabular}

Using the obtained classification, the seven impact categories with higher weighting factor were selected to be presented for this study thus focusing on the most important impact categories for the literature in LCA of AM. However, the category "Land Use" was not considered for this study as most potential impacts come from an Ecoinvent process that has no data available and is based only on assumptions for the raw material composition. As such, the authors of the quantification method recommended not to use the results from this process if the relative influence is high. Finally, the following impact categories (Table 4) were selected:

Table 4. Selected environmental impact categories.

\begin{tabular}{|c|c|c|c|}
\hline Impact Category & Midpoint Unit & Description & References \\
\hline Global Warming & $\mathrm{kg} \mathrm{CO}_{2} \mathrm{eq}$ & $\begin{array}{l}\text { Quantification of the integrated } \\
\text { infrared radiation forcing increase of } \\
\text { a greenhouse gas (GHG) }\end{array}$ & {$[49,50]$} \\
\hline $\begin{array}{l}\text { Ozone Formation, } \\
\text { Human Health }\end{array}$ & $\mathrm{kg} \mathrm{NO}$ eq & Human population intake of ozone & [51] \\
\hline $\begin{array}{l}\text { Ozone Formation, } \\
\text { Terrestrial Ecosystems }\end{array}$ & $\mathrm{kg} \mathrm{NO}$ eq & $\begin{array}{l}\text { Sum of the differences between the } \\
\text { hourly mean ozone concentration and } \\
40 \text { ppb during daylight hours over } \\
\text { the relevant growing season }\end{array}$ & [51] \\
\hline Freshwater Eutrophication & kg P eq & $\begin{array}{l}\text { Measurement of the phosphorus } \\
\text { increase in freshwater }\end{array}$ & {$[52,53]$} \\
\hline $\begin{array}{l}\text { Fine Particulate Matter } \\
\text { Formation }\end{array}$ & $\mathrm{kg} \mathrm{PM}_{2.5} \mathrm{eq}$ & $\begin{array}{l}\text { Particulate emission with a diameter } \\
\text { lower than } 2.5 \mu \mathrm{m} \text {. }\end{array}$ & {$[51]$} \\
\hline Terrestrial Acidification & $\mathrm{kg} \mathrm{SO}_{2} \mathrm{eq}$ & $\begin{array}{c}\text { Quantification of proton increase in } \\
\text { natural soils }\end{array}$ & {$[54]$} \\
\hline Fossil Resource Scarcity & $\mathrm{kg}$ oil eq & $\begin{array}{l}\text { Ratio between the higher heating } \\
\text { value of a fossil resource and the } \\
\text { energy content of crude oil }\end{array}$ & [55] \\
\hline
\end{tabular}

Long-term emissions and infrastructure impacts from the Ecoinvent background data were also included. The results are presented in Figure 3 for the comparison between conventional production and hybrid repair of one mold with 125,000 cycles, in Ecopoints per impact category. 


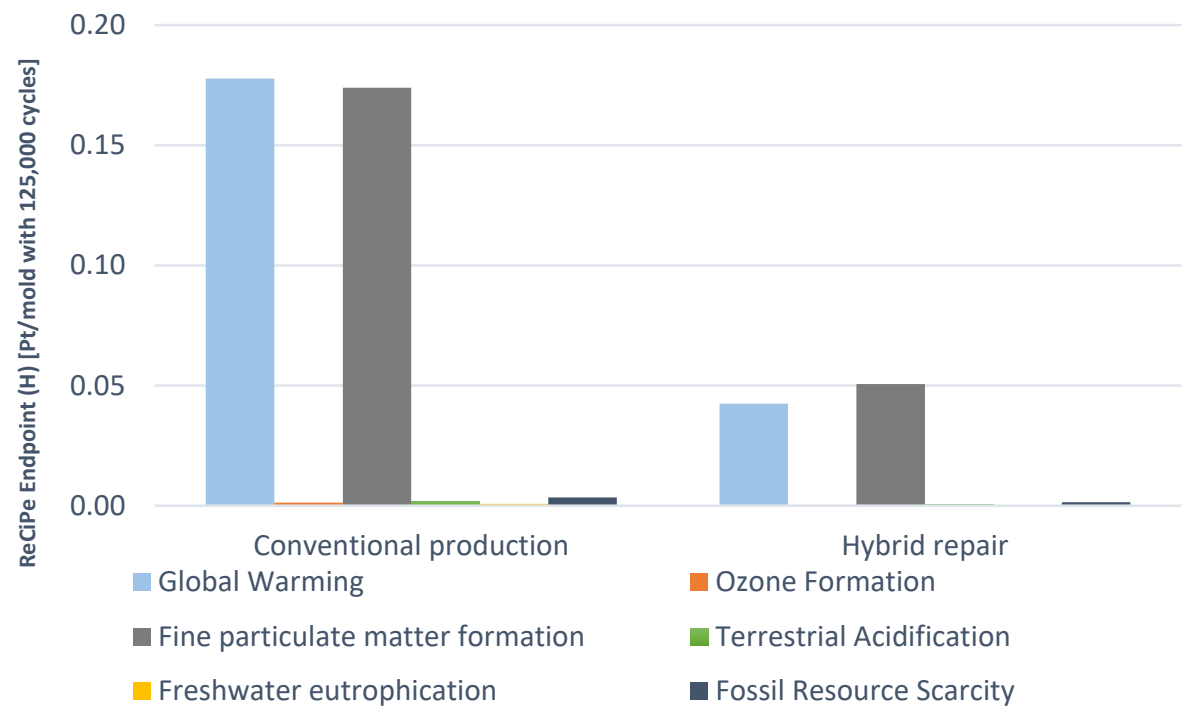

Figure 3. Environmental impact comparison between the conventional production and the hybrid repairing system, expressed in Ecopoints $(\mathrm{Pt})$ through $\operatorname{ReCiPe}$ Endpoint $(\mathrm{H})$ per functional unit—one functional mold with a durability of 125,000 cycles.

The results show that the main impacts are connected with the effects of Global Warming (GW) and fine Particulate Matter Formation (PMF). The second most relevant impact category in this analysis is the Fossil Resource Scarcity, followed by Terrestrial Acidification.

The difference between the conventional and the hybrid repair is $76 \%$ in GW and $71 \%$ in PMF, indicating that there is a strong potential to reduce the environmental impacts by using this technology, together with the benefits of avoiding the consumption of more resources by extending the lifetime of the mold. Since GW and PMF are the most relevant category for this analysis, a more detailed examination into each process step within the scenarios revealed that the main sources of impact in both categories are the samecombustion of fossil fuel for the generation of energy and electricity to be consumed during the production of the process flows. For that, a more specific analysis was conducted on GW through ReCiPe Midpoint $(\mathrm{H})$ as this is the most relevant category identified in the literature analysis (Table 4). Figure 4 presents the carbon footprint for each scenario per functional unit.

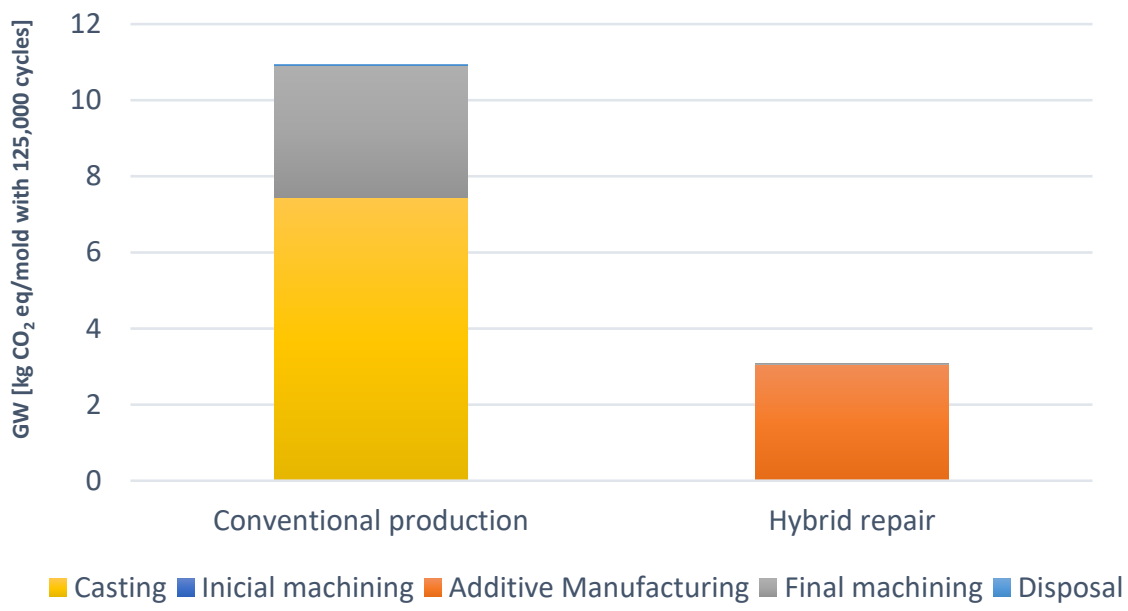

Figure 4. Carbon footprint of each scenario, in $\mathrm{kg}$ of $\mathrm{CO}_{2}$ eq, through the Global Warming category from ReCiPe Midpoint $(\mathrm{H})$ per functional unit-one functional mold with a durability of 125,000 cycles. 
As previously observed, the hybrid repairing process has less environmental impacts than the conventional process. The process steps that contribute the most for the impacts are casting and final machining for the conventional production and the additive production for the hybrid repair. The conventional production scenario generates $10.95 \mathrm{~kg}$ of $\mathrm{CO}_{2}$ eq, where the casting process has $7.44 \mathrm{~kg}$ of $\mathrm{CO}_{2}$ eq $(68 \%$ of total conventional production impacts) and the final machining $3.49 \mathrm{~kg}$ of $\mathrm{CO}_{2}$ eq (32\%). In the casting, most impacts are generated from pig iron production, related to the use of iron and coke. The final machining of the mold has the second highest impacts due to the waste generated by the iron shavings. Considering the impacts from initial machining, additive manufacturing and final machining finishes, the repairing process generates around $2.62 \mathrm{~kg}$ of $\mathrm{CO}_{2}$ eq. In this scenario, the additive manufacturing through the DED system dominates the total impacts due mostly to electricity consumption (43\%), through the contribution of natural gas to the Portuguese electricity mix. Argon consumption also has a high contribution to the total impacts (34\%), mostly because of electricity use in the cryogenic air separation to isolate the gas. The $\mathrm{H} 13$ powder contributes $9 \%$ to the total impacts, where most impacts derive from the presence of molybdenum and chromium in its composition. The initial machining of the damaged part has a contribution of $0.07 \mathrm{~kg}$ of $\mathrm{CO}_{2} \mathrm{eq}$, and the final machining contributes $0.08 \mathrm{~kg}$ of $\mathrm{CO}_{2}$ eq, mostly due to the generated metal waste, being the least contributing process to the total impacts of the hybrid repairing system.

\subsection{Life Cycle Costing (LCC)—Cost Assessment}

The life cycle economic impacts are related to the operation phase of the BAU scenario and the hybrid repair scenario, since it was conducted from the stakeholder perspective of a manufacturer (tooling user) that needs to have a working mold to put back into its glass bottle production system. The result for each scenario is presented in Table 5. Regarding the economic impacts, an estimate from the producers of cast iron molds was given for the total cost to produce a new mold: $€ 1000$. The results for the economic impact of the hybrid system include the man-hours for all stages of active life; as well as equipment usage, material, and energy consumption for the use phase; inactivity and adjustments for the maintenance phase; and environmental costs that would be normally considered externalities to the current conventional economic system. Most of the gathered data are related to laboratorial conditions but easily scalable to an industrial setting. Due to lack of information, the end-of-life and associated costs were not considered.

Table 5. Life cycle economic costs for each scenario for the functional unit of one functional mold with a durability of 125,000 cycles.

\begin{tabular}{ccccc}
\hline Scenarios & Use & Maintenance & Environmental $^{2}$ & Total $^{2}$ \\
\hline Conventional production & $€ 1000$ & - & $€ 3.40$ & $€ 1003.40$ \\
Repairing processes $^{1}$ & $€ 19.74$ & $€ 0.33$ & $€ 2.38$ & $€ 22.45$ \\
\hline
\end{tabular}

${ }^{1}$ Cost results for three repairing processes of one mold, for a durability of 125,000 cycles. ${ }^{2}$ Environmental prices V1.01 (European 2015), adjusted inflation of 1.06\% to Euro 2021.

Most of the accounted costs in this analysis derive from the use phase for each scenario $(99.7 \%$ in the conventional production and $87.9 \%$ in the repairing process). In the conventional scenario, the costs come mainly from the production process of the new mold from sand mold casting, that is usually subcontracted from another business. This is the only cost considered that directly affects the manufacturer of glass bottles. For the repairing processes, the main driver of the costs associated to the use phase are the material and energy consumed during the repairing activities ( $83.1 \%$ of the total use phase costs), where argon is the most expensive consumable in the system, accounting for $38.7 \%$ of the total use phase costs. The $\mathrm{H} 13$ steel is the second most expensive consumption in the repairing operation with $28.4 \%$, followed by labor costs with $13.0 \%$ and electricity $(2.8 \%)$. The most inexpensive cost associated with the operating activities is the individual protective equipment, with $0.1 \%$ of the total costs for this phase. The equipment purchase contributes 
$17 \%$ of the total use phase costs. In maintenance, the costs correspond to $1 \%$ of the total life cycle costs for the repairing, where inactivity costs are the most relevant, with $73.6 \%$ of the total costs for this phase. The registered maintenance activities (chiller filter and water substitution, additives, degreasers, etc.) are negligible considering the total life cycle costs of the repairing activities.

The environmental costs—currently externalities to the economic system-quantify the worth of the affected environmental resources in a European setting. These values can be of interest when comparing scenarios with similar costs to consider the environmental aspect. The results show a clear advantage to the repairing scenario. The environmental costs of repairing are lower than conventional production, indicating lower emissions and environmental damage that can translate into lower carbon taxes in the future. In the conventional scenario, almost all the environmental costs are related to the iron casting. In the repairing scenario, the material and energy consumption during the additive deposition are responsible for $88 \%$ of the total environmental costs.

\subsection{Discussion}

The environmental and economic assessment results are consistent regarding the most relevant processes that can greatly affect the performance of each scenario. The material and energy flows are the main drivers of costs and environmental impacts even when accounting for the machinery acquisition. In the repairing scenario, the amount of argon and powder consumed by the DED can cause significant increase to the operation and maintenance costs. The electricity consumed has more significance in the LCA study, mostly due to the contribution of natural gas to the Portuguese electricity mix, in agreement with recent literature [20,56].

Even when the mold needs to be repaired three times to match the longevity of a new mold, the hybrid repair scenario has significant economic and environmental advantages. These results can vary greatly with the type of damage that occurs in the mold, mainly in the size, geometry, and complexity [18]. The increase of active time in the DED system can greatly increase the consumption of electricity, argon, and powder. When comparing the performance of the repairing with conventional production, a better environmental and economic performance is verified but not guaranteed, as confirmed by the current literature in AM technology [56,57]. As the impacts and costs from the conventional scenario increase with the size of the mold to be produced, due to the proportional increase of resources and waste generation, so does the impacts and costs from the repairing scenario if the damaged area is increased.

It is clear that the repairing can significantly improve the environmental and economic performance of this case study, within the previously described characteristics and assumptions. For other case studies, with larger parts that need to be repaired, the contribution of AM technology can not only avoid the associated impacts of producing a new mold, but also reduce costs and the delayed time due to a damaged part, which was not taken into account in the LCC study. Additionally, the social dimension was not considered, as the lack of information and an established methodology significantly limited the approach. Most literature on sustainability analysis does not consider the social aspects of AM [27], although there may be underlying social effects when opting for this technology, this may be an interesting research topic to complement the presented results.

\section{Conclusions and Limitations}

The main purpose of this study was to contribute with more data regarding the performance and capabilities of the DED technology in the development of sustainable and competitive European manufacturing. As such, the research activities successfully created a life cycle inventory on the operation of a DED system with foreground data from laboratorial measurements, invoices, and sensors (see Appendix A) with a high level of reliability. With the gathered information, it was possible to present results for the 
environmental and economic axis of sustainability performance in the scope of repairing capabilities.

In the results of the LCA study, the reduction on resource consumption and the extended lifetime of the mold translates into significant environmental impact reduction when compared with conventional production. For the LCC study, the results indicate that there is a need for higher efficiency of argon and powder consumption since these flows are the highest contributors to the total life cycle costs of repairing. The environmental and economic performance of the hybrid repairing system has the potential to be significantly better than the conventional production, even considering that the repaired mold has a third of the durability of the new one. Since most data for the conventional scenario came from the literature and the life cycle database, a more accurate detailing of the conventional iron casting process is necessary to corroborate these findings.

The economic gains for the manufacturer in the hybrid repair scenario are interlinked with the deferred costs of third parties to produce a new mold that can take more time to be available for integration in the production line. The cost for this time reduction can be integrated in future studies. Another unquantified advantage is the capacity to upgrade the damaged mold into new designs and customization, which can potentially generate high-value products with lower economic effort. Other effects, such as the social dimension must be considered for future studies to integrate the three pillars of the life cycle sustainability assessment (LCSA).

The presented impacts and costs associated with the repairing scenario assume that the damage that occurs in the mold is relatively similar every time. Furthermore, the case study considered a small, damaged area, when compared with the total area of the mold. Since the environmental and economic performance is directly associated with the consumption of materials and energy in the deposition phase, by comparing small repairing areas with the production of a new mold, it is clear that this technology can have significant reductions in costs and environmental impacts for case studies with large dimensions, complex geometry, or customized design. Additionally, most case studies in the literature focus on full production of parts and do not assess key process steps to the future circular industrial paradigm, such as repairing, refurbishment or retrofitting. As such, the results from this study can serve as basis for future research in the capabilities of $\mathrm{AM}$ in a circular economy perspective.

In conclusion, through strategic application of life cycle-based approaches in the tooling and manufacturing industry, the DED hybrid manufacturing technology can play a significant role in the path towards a circular economy and sustainable manufacturing.

Author Contributions: Methodology, J.R.G. and S.M.P.; software: J.R.G. and S.C.; validation, J.R.M., J.S., L.O. and S.E.; formal analysis, J.R.G.; investigation, J.R.G. and S.C.; resources, J.R.M., J.S., L.O. and S.E.; data curation, J.R.G., S.M.P., J.R.M. and J.S.; writing-original draft preparation, J.R.G. and S.M.P.; writing-review and editing, J.R.G., S.M.P. and S.C.; visualization, J.R.G.; supervision, L.O.; project administration, S.E. All authors have read and agreed to the published version of the manuscript.

Funding: The authors acknowledge the funding support given by the European Regional Development Fund (ERDF) through the PORTUGAL2020 Program, Mobilizing Programs in the framework of the Project TOOLING4G-Advanced Tools for Smart Manufacturing, reference number POCI01-0247-FEDER-024516. The present work was done and funded under the scope of the project Add.Additive - add additive manufacturing to Portuguese industry (ANI | P2020 | POCI-01-0247FEDER-024533), co-funded by Portugal 2020 and FEDER, through COMPETE 2020-Operational Program for Competitiveness and Internationalization.

Institutional Review Board Statement: Not applicable.

Informed Consent Statement: Not applicable.

Conflicts of Interest: The authors declare no conflict of interest. 


\section{Appendix A}

Table A1. Matching production stages and processes from the Ecoinvent v3.7.1 database for the conventional production scenario.

\begin{tabular}{cccc}
\hline Production Stages & Ecoinvent Process & Units & Value \\
\hline Casting & Cast iron \{RER\} | production | APOS, U & $\mathrm{kg}$ & 4.55 \\
\hline Machining & $\begin{array}{c}\text { Cast iron removed by milling, average }\{\text { RER\} | cast iron milling, } \\
\text { average | APOS, U }\end{array}$ & $\mathrm{kg}$ & 1.047 \\
\hline \multirow{2}{*}{ End-of-life } & $\begin{array}{c}\text { Scrap steel } \begin{array}{c}\text { Europe without Switzerland\} | treatment of scrap } \\
\text { steel, inert material landfill | APOS, S }\end{array} \\
\mathrm{k}\end{array}$ & $\mathrm{kg}$ & 4.55 \\
\hline
\end{tabular}

Table A2. Matching production stages and processes from the Ecoinvent v3.7.1 database for the hybrid repair scenario.

\begin{tabular}{|c|c|c|c|}
\hline Production Stages & Ecoinvent Process & Units & Value \\
\hline \multirow{2}{*}{ Initial Machining } & $\begin{array}{c}\text { Chromium steel removed by milling, average }\{\text { RER }\} \text { I chromium } \\
\text { steel milling, average | APOS, U (adapted) }{ }^{1}\end{array}$ & g & 14.5 \\
\hline & $\begin{array}{c}\text { Scrap steel }\{\text { Europe without Switzerland\} | treatment of scrap } \\
\text { steel, inert material landfill | APOS, S }\end{array}$ & $\mathrm{g}$ & 14.5 \\
\hline \multirow{12}{*}{ H13 powder } & Tungsten & $\mathrm{kg}$ & 0.005 \\
\hline & Vanadium & $\mathrm{kg}$ & 0.089 \\
\hline & $\begin{array}{c}\text { Iron ore concentrate }\{\text { GLO }\} \text { | market for iron ore } \\
\text { concentrate } \mid \text { APOS, U }\end{array}$ & $\mathrm{kg}$ & 0.808 \\
\hline & Chromium $\{$ GLO $\}$ I market for I APOS, S & $\mathrm{kg}$ & 0.055 \\
\hline & Molybdenum $\{\mathrm{GLO}\} \mid$ | market for | APOS, S & $\mathrm{kg}$ & 0.013 \\
\hline & Manganese $\{\mathrm{GLO}\}$ | market for I APOS, S & $\mathrm{kg}$ & 0.006 \\
\hline & Silicon, metallurgical grade $\{\mathrm{GLO}\}$ I market for I APOS, S & $\mathrm{kg}$ & 0.0086 \\
\hline & Phosphorus, white, liquid $\{$ RER $\}$ I production I APOS, S & $\mathrm{kg}$ & 0.00016 \\
\hline & Carbon monoxide $\{$ RER $\} \mid$ market for $\mid$ APOS, S & $\mathrm{kg}$ & 0.0188 \\
\hline & Sulfur $\{$ GLO $\}$ I market for I APOS, S & $\mathrm{kg}$ & 0.00015 \\
\hline & Cobalt $\{$ GLO $\}$ I market for I APOS, U & $\mathrm{kg}$ & 0.0003 \\
\hline & $\begin{array}{l}\text { Heat, central or small-scale, natural gas }\{\mathrm{CH}\} \mid \text { natural gas, burned } \\
\text { in micro gas turbine, } 100 \mathrm{kWe} \mid \text { APOS, S }\end{array}$ & $\mathrm{kWh}$ & 0.46 \\
\hline \multirow{4}{*}{ Argon ${ }^{2}$} & Argon, liquid $\{$ RER $\}$ I market for argon, liquid I APOS, U & $\mathrm{kg}$ & 1.619 \\
\hline & Steel, unalloyed $\{$ GLO $\}$ | market for I APOS, U & $\mathrm{kg}$ & 0.0063 \\
\hline & Argon (emissions to air) & $\mathrm{kg}$ & 1.619 \\
\hline & $\begin{array}{c}\text { Scrap steel \{Europe without Switzerland\} | treatment of scrap } \\
\text { steel, inert material landfill | APOS, S }\end{array}$ & $\mathrm{kg}$ & 0.0063 \\
\hline \multirow{5}{*}{ DED deposition } & H13 powder & $\mathrm{g}$ & 38.45 \\
\hline & Argon & $\mathrm{m}^{3}$ & 0.123 \\
\hline & $\begin{array}{c}\text { Electricity, medium voltage }\{\mathrm{PT}\} \text { I market for I APOS, U (updated } \\
\text { to } 2020 \text { ) }\end{array}$ & $\mathrm{kWh}$ & 1.4345 \\
\hline & $\begin{array}{c}\text { Electric arc furnace dust }\{\mathrm{CH}\} \mid \text { treatment of electric arc furnace } \\
\text { dust, residual material landfill | APOS, S }\end{array}$ & g & 7.69 \\
\hline & DED system & $\mathrm{p}$ & $9.19 \times 10^{-6}$ \\
\hline \multirow{2}{*}{ Final machining } & $\begin{array}{c}\text { Chromium steel removed by milling, average }\{\text { RER }\} \text { | chromium } \\
\text { steel milling, average I APOS, U (adapted) }{ }^{1}\end{array}$ & g & 16.26 \\
\hline & $\begin{array}{c}\text { Scrap steel }\{\text { Europe without Switzerland }\} \text { I treatment of scrap } \\
\text { steel, inert material landfill I APOS, S }\end{array}$ & g & 16.26 \\
\hline
\end{tabular}

\footnotetext{
${ }^{1}$ Steel material removed. ${ }^{2} 85 \mathrm{~kg}$ of steel bottle with $10.5 \mathrm{~m}^{3}$ of argon, equivalent to $17 \mathrm{~kg}$.
} 


\section{References}

1. Shim, D.S.; Baek, G.Y.; Seo, J.S.; Shin, G.Y.; Kim, K.P.; Lee, K.Y. Effect of layer thickness setting on deposition characteristics in direct energy deposition (DED) process. Opt. Laser Technol. 2016, 86, 69-78. [CrossRef]

2. Javidani, M.; Arreguin-Zavala, J.; Danovitch, J.; Tian, Y.; Brochu, M. Additive Manufacturing of AlSi10Mg Alloy Using Direct Energy Deposition: Microstructure and Hardness Characterization. J. Therm. Spray Technol. 2017, 26, 587-597. [CrossRef]

3. Attaran, M. The rise of 3-D printing: The advantages of additive manufacturing over traditional manufacturing. Bus. Horiz. 2017, 60, 677-688. [CrossRef]

4. Ford, S.; Despeisse, M. Additive manufacturing and sustainability: An exploratory study of the advantages and challenges. J. Clean. Prod. 2016, 137, 1573-1587. [CrossRef]

5. Gibson, I.; Rosen, D.; Stucker, B.; Khorosani, M. Additive Manufacturing Technologies; Springer: Cham, Switzerland, 2021; Volume 89, ISBN 978-3-030-56127-7.

6. Dippenaar, D.J.; Schreve, K. 3D printed tooling for vacuum-assisted resin transfer moulding. Int. J. Adv. Manuf. Technol. 2013, 64, 755-767. [CrossRef]

7. Ramesh, A. Additive Manufacturing for Tooling: Applications and Benefits. Available online: https://www.amchronicle.com/ insights/applications-and-benefits-of-am-in-tooling/ (accessed on 10 December 2021).

8. Cotteleer, M.; Neier, M.; Crane, J. 3D Opportunity in Tooling: Additive Manufacturing Shapes the Future; Delloit University Press: Westlake, OH, USA, 2014; p. 12.

9. Morrow, W.R.; Qi, H.; Kim, I.; Mazumder, J.; Skerlos, S.J. Environmental aspects of laser-based and conventional tool and die manufacturing. J. Clean. Prod. 2007, 15, 932-943. [CrossRef]

10. ISO 14040; Environmental Management-Life Cycle Assessment-Principles and Framework. International Standardized Organization: Geneve, Switzerland, 2006.

11. ISO 14044; Environmental Management—Life Cycle Assessment—Requirements and Guidelines. International Standardized Organization: Geneve, Switzerland, 2006.

12. Gundes, S. The Use of Life Cycle Techniques in the Assessment of Sustainability. Procedia Soc. Behav. Sci. 2016, 216, 916-922. [CrossRef]

13. Dong, Y.; Miraglia, S.; Manzo, S.; Georgiadis, S.; Sørup, H.J.D.; Boriani, E.; Hald, T.; Thöns, S.; Hauschild, M.Z. Environmental sustainable decision making- The need and obstacles for integration of LCA into decision analysis. Environ. Sci. Policy 2018, 87, 33-44. [CrossRef]

14. Zhang, X.; Zhang, M.; Zhang, H.; Jiang, Z.; Liu, C.; Cai, W. A review on energy, environment and economic assessment in remanufacturing based on life cycle assessment method. J. Clean. Prod. 2020, 255, 120160. [CrossRef]

15. Liu, Z.; Jiang, Q.; Cong, W.; Li, T.; Zhang, H.C. Comparative study for environmental performances of traditional manufacturing and directed energy deposition processes. Int. J. Environ. Sci. Technol. 2018, 15, 2273-2282. [CrossRef]

16. Islam, F. Sustainability Assessment of Direct Energy Deposition (DED) Based Hybrid Manufacturing Using Life Cycle Assessment (LCA) Method; ProQuest Dissertations Publishing: Morgantown, WV, USA, 2021.

17. Luo, Y.; Ji, Z.; Leu, M.C.; Caudill, R. Environmental performance analysis of solid freeform fabrication processes. IEEE Int. Symp. Electron. Environ. 1999, 1-6. [CrossRef]

18. Kellens, K.; Mertens, R.; Paraskevas, D.; Dewulf, W.; Duflou, J.R. Environmental Impact of Additive Manufacturing Processes: Does AM Contribute to a More Sustainable Way of Part Manufacturing? In Proceedings of the Procedia CIRP, Kamakura, Japan, 8-10 March 2017.

19. Faludi, J.; Baumers, M.; Maskery, I.; Hague, R. Environmental Impacts of Selective Laser Melting: Do Printer, Powder, Or Power Dominate? J. Ind. Ecol. 2017, 21, S144-S156. [CrossRef]

20. Walachowicz, F.; Bernsdorf, I.; Papenfuss, U.; Zeller, C.; Graichen, A.; Navrotsky, V.; Rajvanshi, N.; Kiener, C. Comparative Energy, Resource and Recycling Lifecycle Analysis of the Industrial Repair Process of Gas Turbine Burners Using Conventional Machining and Additive Manufacturing. J. Ind. Ecol. 2017, 21, S203-S215. [CrossRef]

21. Faludi, J.; Bayley, C.; Bhogal, S.; Iribarne, M. Comparing environmental impacts of additive manufacturing vs traditional machining via life-cycle assessment. Rapid Prototyp. J. 2015, 21, 14-33. [CrossRef]

22. Kafara, M.; Süchting, M.; Kemnitzer, J.; Westermann, H.-H.; Steinhilper, R. Comparative Life Cycle Assessment of Conventional and Additive Manufacturing in Mold Core Making for CFRP Production. Procedia Manuf. 2017, 8, 223-230. [CrossRef]

23. Bekker, A.C.M.; Verlinden, J.C. Life cycle assessment of wire + arc additive manufacturing compared to green sand casting and CNC milling in stainless steel. J. Clean. Prod. 2018, 177, 438-447. [CrossRef]

24. Atzeni, E.; Salmi, A. Economics of additive manufacturing for end-usable metal parts. Int. J. Adv. Manuf. Technol. 2012, 62, 1147-1155. [CrossRef]

25. Weller, C.; Kleer, R.; Piller, F.T. Economic implications of 3D printing: Market structure models in light of additive manufacturing revisited. Int. J. Prod. Econ. 2015, 164, 43-56. [CrossRef]

26. Lindemann, C.; Jahnke, U.; Moi, M.; Koch, R. Impact and Influence Factors of Additive Manufacturing on Product Lifecycle Costs. In Proceedings of the International Solid Freeform Fabrication Symposium, Austin, TX, USA, 12-14 August 2013; pp. $998-1009$.

27. Ribeiro, I.; Matos, F.; Jacinto, C.; Salman, H.; Cardeal, G.; Carvalho, H.; Godina, R.; Peças, P. Framework for life cycle sustainability assessment of additive manufacturing. Sustainability 2020, 12, 929. [CrossRef] 
28. Pesonen, H.L. Environmental Management of Value Chains: Promoting Life-cycle Thinking in Industrial Networks. Greener Manag. Int. 2001, 33, 45-58. [CrossRef]

29. Roth, H.R.; Lewis, M.; Hancock, L. The Green Building Materials Manual; Springer: Cham, Switzerland, 2021; ISBN 9783030648879.

30. Gheewala, S.H.; Silalertruksa, T. Life Cycle Thinking in a Circular Economy. In An Introduction to Circular Economy; Liu, L., Ramakrishna, S., Eds.; Springer Singapore: Sigapore, 2021.

31. Gouveia, J.R. Life Cycle Inventory of a Direct Energy Deposition system. Climate, 2022; unpublished manuscript.

32. Wernet, G.; Bauer, C.; Steubing, B.; Reinhard, J.; Moreno-Ruiz, E.; Weidema, B. The ecoinvent database version 3 (part I): Overview and methodology. Int. J. Life Cycle Assess. 2016, 21, 1218-1230. [CrossRef]

33. Mahamood, R.M.; Akinlabi, E.T. Processing Parameters Optimization for Material Deposition Efficiency in Laser Metal Deposited Titanium Alloy. Lasers Manuf. Mater. Process. 2016, 3, 9-21. [CrossRef]

34. APREN Balanço da Produção de Eletricidade de Portugal Continental (agosto de 2020). Available online: https://www.apren.pt/ pt/energias-renovaveis / producao (accessed on 14 September 2020).

35. Direção-Geral de Energia e Geologia (DGEG) Produção anual e potência instalada. Available online: https://www.dgeg.gov.pt/ pt/estatistica/energia/eletricidade/producao-anual-e-potencia-instalada/ (accessed on 10 December 2021).

36. Eurostat; Instituto Nacional de Estatística Electricity prices for domestic and industrial users (Euro/ECU). Available online: https:/ / www.pordata.pt/Europa/Preços+da+electricidade+para+utilizadores+domésticos+e+industriais+(Euro+ECU)-1 477-313029 (accessed on 10 December 2021).

37. Pré Consultants Simapro. Available online: https:// simapro.com/ (accessed on 10 December 2021).

38. Huijbregts, M.A.J.; Steinmann, Z.J.; Elshout, P.M.F.; Stam, G.; Verones, F.; Vieira, M.D.M.; Zijp, M.; van Zelm, R. ReCiPe 2016: A Harmonized Life Cycle Impact Assessment Method at Midpoint and Enpoint Level—Report 1: Characterization; National Institute for Public Health and the Environment: Bilthoven, The Netherlands, 2016.

39. Torres-Carrillo, S.; Siller, H.R.; Vila, C.; López, C.; Rodríguez, C.A. Environmental analysis of selective laser melting in the manufacturing of aeronautical turbine blades. J. Clean. Prod. 2020, 246. [CrossRef]

40. Wilson, J.M.; Piya, C.; Shin, Y.C.; Zhao, F.; Ramani, K. Remanufacturing of turbine blades by laser direct deposition with its energy and environmental impact analysis. J. Clean. Prod. 2014, 80, 170-178. [CrossRef]

41. Bourhis, F.L.; Kerbrat, O.; Dembinski, L.; Hascoet, J.Y.; Mognol, P. Predictive model for environmental assessment in additive manufacturing process. Procedia CIRP 2014, 15, 26-31. [CrossRef]

42. Serres, N.; Tidu, D.; Sankare, S.; Hlawka, F. Environmental comparison of MESO-CLAD®process and conventional machining implementing life cycle assessment. J. Clean. Prod. 2011, 19, 1117-1124. [CrossRef]

43. Paris, H.; Mokhtarian, H.; Coatanéa, E.; Museau, M.; Ituarte, I.F. Comparative environmental impacts of additive and subtractive manufacturing technologies. CIRP Ann. Manuf. Technol. 2016, 65, 29-32. [CrossRef]

44. Ma, J.; Harstvedt, J.D.; Dunaway, D.; Bian, L.; Jaradat, R. An exploratory investigation of Additively Manufactured Product life cycle sustainability assessment. J. Clean. Prod. 2018, 192, 55-70. [CrossRef]

45. Kellens, K.; Renaldi, R.; Dewulf, W.; Kruth, J.P.; Duflou, J.R. Environmental impact modeling of selective laser sintering processes. Rapid Prototyp. J. 2014, 20, 459-470. [CrossRef]

46. Böckin, D.; Tillman, A.M. Environmental assessment of additive manufacturing in the automotive industry. J. Clean. Prod. 2019, 226, 977-987. [CrossRef]

47. Baumers, M.; Tuck, C.; Wildman, R.; Ashcroft, I.; Rosamond, E.; Hague, R. Transparency Built-in: Energy Consumption and Cost Estimation for Additive Manufacturing. J. Ind. Ecol. 2013, 17, 418-431. [CrossRef]

48. Kellens, K.; Yasa, E.; Renaldi, R.; Dewulf, W.; Kruth, J.P.; Duflou, J.R. Energy and Resource Efficiency of SLS/SLM Processes. Phys. Rev. E 2011, 2011, 1-16.

49. Intergovernmental Panel on Climate Change. Climate Change 2013-The Physical Science Basis: Working Group I Contribution to the Fifth Assessment Report of the Intergovernmental Panel on Climate Change; Cambridge University Press: Cambridge, UK, 2014; ISBN 9781107057999.

50. Joos, F.; Roth, R.; Fuglestvedt, J.S.; Peters, G.P.; Enting, I.G.; von Bloh, W.; Brovkin, V.; Burke, E.J.; Eby, M.; Edwards, N.R.; et al. Carbon dioxide and climate impulse response functions for the computation of greenhouse gas metrics: A multi-model analysis. Atmos. Chem. Phys. 2013, 13, 2793-2825. [CrossRef]

51. van Zelm, R.; Preiss, P.; van Goethem, T.; Van Dingenen, R.; Huijbregts, M. Regionalized life cycle impact assessment of air pollution on the global scale: Damage to human health and vegetation. Atmos. Environ. 2016, 134, 129-137. [CrossRef]

52. Azevedo, L.B.; Henderson, A.D.; Van Zelm, R.; Jolliet, O.; Huijbregts, M.A.J. Assessing the importance of spatial variability versus model choices in life cycle impact assessment: The case of freshwater eutrophication in Europe. Environ. Sci. Technol. 2013, 47, 13565-13570. [CrossRef]

53. Azevedo, L.B.; van Zelm, R.; Elshout, P.M.F.; Hendriks, A.J.; Leuven, R.S.E.W.; Struijs, J.; de Zwart, D.; Huijbregts, M.A.J. Species richness-phosphorus relationships for lakes and streams worldwide. Glob. Ecol. Biogeogr. 2013, 22, 1304-1314. [CrossRef]

54. Roy, P.O.; Azevedo, L.B.; Margni, M.; van Zelm, R.; Deschênes, L.; Huijbregts, M.A.J. Characterization factors for terrestrial acidification at the global scale: A systematic analysis of spatial variability and uncertainty. Sci. Total Environ. 2014, 500-501, 270-276. [CrossRef]

55. Jungbluth, N.; Frischknecht, R. Cumulative energy demand. In Implementation of Life Cycle Impact Assessment Methods; Hischier, R., Weidema, B., Eds.; Ecoinvent Centre: Dübendorf, Switzerland, 2010; pp. 33-40. 
56. Liu, Z.; Jiang, Q.; Ning, F.; Kim, H.; Cong, W.; Xu, C.; Zhang, H.C. Investigation of energy requirements and environmental performance for additive manufacturing processes. Sustainability 2018, 10, 3606. [CrossRef]

57. Solaimani, S.; Parandian, A.; Nabiollahi, N. A holistic view on sustainability in additive and subtractive manufacturing: A comparative empirical study of eyewear production systems. Sustainability 2021, 13, 10775. [CrossRef] 